\title{
Los comuneros: un apunte histórico
}

\section{Luz María Cruz de Galindo}

Arbor CLXV, 652 (Abril 2000), 731-745 pp.

\section{Introducción}

Las colectividades organizadas poseen un espíritu que es fruto preciado y obra capital de innumerables generaciones, síntesis de progresos alcanzados a costa de sacrificios, resultado de abnegaciones y heroísmos sin cuento: el instrumento de su formación es la educación que moldea los espíritus al calor de unas ideas y les infunde ciertos sentimientos que dan cohesión porque unifican en lo propio. Todo ello probado y acrisolado en el transcurso del tiempo. Se trata de colectividades cuyos rasgos característicos son la permanencia, la resistencia a las innovacionesmientras no prueben que esto supone un enriquecimiento-, pues valoran tanto lo que tienen que sólo adoptan lo que comprueban que es mejor. Asimismo se caracterizan por una vivacidad extraordinaria que triunfa sobre todos los obstáculos ${ }^{1}$.

En el presente estudio veremos cuáles de estos rasgos se dan en las Comunidades Castellanas durante los primeros años de reinado del emperador Carlos a la luz del moderno debate sobre el comunitarismo.

\section{Un episodio: La rebelión comunera ${ }^{2}$}

A principios del Siglo XVI encontramos en Castilla un inestable equilibrio político-social entre los tres grandes poderes: realeza, nobleza y burguesía municipal, con un trasfondo del problema campesino. En apariencia existe paz, aunque los grupos nobiliarios han ido incrementando su poder a costa del país, sus tierras y sus campesinos, a quienes explotan. El dominio de la nobleza es ancestral y goza de todo tipo de privilegios jurídicos, fiscales y de honor, y de una organización familiar basada en el linaje. En teoría los nobles son los responsables de guardar la paz 
y proteger a los distintos grupos sociales, pero su ambición voraz finalmente genera conflictos y luchas intestinas. Falta contrarrestar el poder de las clases dominantes, la gran propiedad en manos de los aristócratas abarca incluso sectores no nobiliarios. Los tesoros inclinan la balanza sin dar señales de algún tipo de equilibrio. Entre 1520 y 1521 se vive un liderazgo centrado en las autoridades municipales, cuyos representantes son burgueses o patricios urbanos: comerciantes, juristas o administradores, encargados del cuidado de las ciudades y villas. La situación de los campesinos es muy dura - aunque es difícil generalizar en un ámbito geográfico tan amplio y variado- debido a los sistemas de tenencia de la tierra, al desarrollo de la ganadería lanar y al peso de los impuestos. Son libres, pero sólo emergen de la pobreza algunos labradores propietarios. Muchos no disponen de tierra y trabajan como jornaleros eventuales. En general la condición del campesinado es mejor en tierras de realengo que en las señoriales, como las castellanas, porque la proximidad de los señores asfixia la iniciativa de los campesinos para distribuir el fruto de su trabajo.

Así encontramos un mundo urbano que, pese a las características específicas de las distintas ciudades, tiene un rasgo común: el acrecentamiento de grupos oligárquicos - el patriciado urbano- que controla las instituciones de gobierno. Todo ello va cavando un foso cada vez mayor entre éstas - una cuantas familias de cada lugar-y el resto del común de la gente asalariada, de pequeños mercaderes, de artesanos y mundo gremial $^{3}$. Por eso, no podemos hablar estrictamente de fuertes vínculos comunitarios en Castilla, la inconformidad está latente y los primeros años del reinado de Carlos $\mathrm{V}$ son el detonador del descontento. Chocan entonces la nobleza y la oligarquía municipal; a su vez esta oligarquía se enfrenta con la política absolutista del monarca.

Ante el disgusto de las disposiciones del nuevo rey, la Comunidad de Toledo constituye una Junta de gobierno y alienta a las ciudades castellanas a buscar juntos el remedio contra el mal gobierno. Las ciudades del Duero se proclaman en rebelión y organizan su propia comunidad ${ }^{4}$. En pocos días hacen lo mismo otras ciudades. El fuego comunero prende por todas partes. En los primeros momentos el alzamiento parece no afectar a la alta nobleza castellana, que se coloca a la expectativa. Pero pronto en algunos lugares de señorío los vasallos se alzan contra los señores. Aquí y allá se dan violencias semejantes, aunque con notas peculiares que quitan unidad al movimiento. Entre las comunidades sublevadas van surgiendo algunos cabecillas, muy respetados por los comuneros. Sobre todos ellos destaca el caballero toledano Juan Padilla, quien ejerce un indudable liderazgo. 
Los comuneros, firmes en su actitud de protesta y resistencia, comprenden la necesidad de convenir un plan de conducta para unir esfuerzos. Toda Castilla se pone en armas, lo que da ocasión a las ciudades de enviar sus representantes a Ávila, donde se organiza una Junta Superior de Gobierno, llamada Junta Santa ${ }^{5}$, que en cierta forma es un poder en contra del poder, un antigobierno de un grupo minoritario. Lo novedoso es «el pacto de hermandad que juraron las ciudades sublevadas, prometiendo el socorro de todas a cualquiera de ellas que lo requiriese y comprometiéndose a levantarse en armas en el caso de que cualquier rey o señor quisiese quebrantar a lo que concertare en estas $<<$ Cortes $>>$ y $<<$ Junta $>>^{6}$ ». El movimiento parece triunfar en todas partes. «A la voz $<<$ comunidad $>>$ el pueblo se arremolina y afluye, dispuesto a luchar por una causa que, además de ser nacional, es la suya ${ }^{7} »$.

Esta conducta refleja la unión - contra el intruso- para defender el estilo de vida y de cultura de las comunidades. Se logra, aunque sea momentáneamente, un espíritu comunitario donde se lucha por una causa nacional, propia, frente a quien se considera un injusto agresor. Tal reacción es frecuente en el acontecer histórico: aparece la unión como consecuencia del rechazo a un enemigo común, pero se trata de una unidad muy poco sólida, pues no se persiguen exactamente los mismos fines. Todos saben lo que no quieren, pero no se han puesto de acuerdo en lo que quieren. Eso nos muestra que es mejor la unidad basada en proyectos y objetivos comunes. Sin embargo, el rechazo puede ser punto de partida, pero de inmediato hay que ofrecer vías constructivas para madurar la unión. Esto no sucede en el episodio que nos ocupa: finalmente los comuneros disminuyen mermados por las deserciones, por la falta de disciplina, la atracción de la rapiña o por el simple cansancio. Así, son alcanzados por la caballería realista en Villalar, el 23 de abril de 1521, cuando una lluvia pertinaz empieza a desbaratar la formación de los inconformes. El reino se pacifica al precio de la pérdida de sus libertades y el incuestionable sometimiento al rey. El movimiento comunero fracasa por la falta de unidad de los elementos del grupo: al romperse el inestable equilibrio político-social y al surgir la rebelión no se logra la cohesión suficiente, por las divisiones internas de las comunidades. La razón del triunfo realista es precisamente el foso profundo - del que hemos hablado- entre la oligarquía de cada ciudad y el resto de los integrantes de la comunidad, y la ayuda de algunos importantes nobles a la causa del Emperador.

En esas mismas fechas —entre 1519 y 1523 - los reinos de Valencia y Mallorca se ven agitados por las luchas de las Germanías o Hermandades de menestrales valencianos, contra una nobleza corrompida que detenta 
las funciones de mando. Para descubrir cómo emerge el sentido comunitario en defensa de lo propio, siempre ayuda la comparación entre las diferencias y similitudes de algunos movimientos sociales que, en el caso de las Germanías y las Comunidades, son muy ilustrativas, pues ambos coinciden en el mismo país, en el momento histórico y las gobierna la misma autoridad. El movimiento comunero es netamente político y pretende conseguir un gobierno autóctono, las Germanías se originan por descontentos de tipo social que quieren un gobierno honesto con representatividad de las diversas clases sociales; reflejan la oposición popular al poder de la aristocracia, y el deseo de mantener la autonomía. Los comuneros carecen de armamento, las Germanías lo tienen para defenderse del enemigo externo (los piratas). La rebelión comunera no busca independizarse del rey; las Germanías sí, y no sólo del rey, también de la nobleza, que mantiene la unidad política a costa de la explotación de los gobernados. Esto exacerba el sentimiento de comunidad del pueblo, que se rebela.

Los campesinos no apoyan ninguno de los dos movimientos, excepto en Mallorca. Ambas rebeliones tienen problemas sociopolíticos que en las Germanías se agravan por el desenfreno sexual de los nobles con las moriscas. En ambos casos se trata de movimientos regionales en tierras de señorío o realengo, pero las Germanías tenían más probabilidades de éxito por sus condiciones geográficas. En los dos conflictos hay elementos que propician el espíritu comunitario, pero en las Comunidades, al final, se anestesió tal espíritu y faltó fuerza para lograr los propósitos e ideales de las sociedades castellanas.

\section{2. ¿Unidad política versus sentimiento de comunidad?}

La comunidad tal y como la entiende el comunitarismo, es una agrupación organizada de personas que se perciben como unidad social, cuyos miembros participan de algún rasgo, interés, elemento objetivo o función común, con conciencia de pertenencia y valores compartidos.

Se trata de un bien intrínseco para todos los que forman parte de ella, ya sea como generalización psicológica descriptiva, lo que significa que los seres humanos tienen necesidad de pertenencia; o como generalización normativa, en donde la comunidad es un bien objetivo para sus integrantes. Una comunidad orgánica se ordena a la idea del bien común y valores compartidos por una ciudadanía activa, que participa y trabaja en y para su grupo social. Si esto no se da existe el riesgo de caer en el autoritarismo o la desintegración.

La pertenencia a una comunidad otorga a sus integrantes ciertos derechos y deberes. Es un grupo que no ha sido formado por deliberadas re- 
flexiones de sus componentes, se constituye en forma natural y espontánea, se vive en ella y desde ella, y ahí se desarrollan las personas unidas por la solidaridad. Sin embargo, el estar situados en una determinada área geográfica no es requisito indispensable para ser comunidad, la conciencia comunitaria puede originarse en los vínculos de sangre o en tradiciones comunes. Una comunidad no es un lugar concreto, sino un conjunto de atributos ${ }^{8}$. No obstante, por haber nacido en el mismo suelo se tienen experiencias —climatológicas, de paisaje, etc-, que producen coincidencias unificadoras.

En la comunidad existe una manera de ser - un estilo de vida y de cultura - con cierta organización y simetría. La unión no se da por una mera suma de elementos, sino por el sentimiento de comunidad que vincula a los hombres entre sí, o al menos a la mayoría de sus integrantes. Asimismo se ha de contar con una estructura organizativa básica, una unidad politica, que permita la participación de todos en las tareas del bien común. El problema surge cuando la unidad política reprime o asfixia el espíritu comunitario, o cuando la comunidad se desarticula por falta de organización. Además, la historia nos muestra que sólo muy lentamente se consigue la ampliación de las vinculaciones comunitarias a ámbitos de creciente extensión espacial y creciente distancia física entre los hombres.

El sentimiento de comunidad se basa en la conciencia de pertenencia a una misma entidad histórico-política por parte de todos, es el origen de la solidaridad para un mismo destino, superior a la unión o separación interpersonal más o menos particularista. Para fomentar el sentimiento comunitario no ha de caerse en la utopía de eliminar los particularismos, hay que coordinarlos, pues lo habitual es que algunos persistan. El sistema social - muchas veces sirviéndose de la ley - tiene que reducirlos a límites absorbibles sin que se produzcan conflictos que pongan en peligro el propio orden básico de la comunidad nacional.

En ocasiones el sentimiento de comunidad es precario y los vínculos solidarios muy débiles; las comunidades se encuentran internamente desgarradas por la existencia de grupos antagónicos en la población-territorio y sólo por la imposición incluso violenta de la clase en el poder, se mantiene la unidad. Aparecen entonces lo que podríamos llamar sociedades globales artificiales, donde el sentimiento de comunidad se ha desvanecido, aunque exista unidad política.

Desde el momento en que las antiguas ciudades con vida y estatutos propios -integradas o no en sociedades globales más amplias- pasan a integrarse en unidades de espacio-territorio de mayor amplitud, se convier- 
te en fenómeno habitual en la historia los casos de existencia de una unidad organizativa - unidad política - junto a una mal lograda o deficiente unidad psicológica — sentimiento de comunidad—?.

Las comunidades castellanas -agrupaciones de varias villas y aldeas, e incluso pueblos integrados en torno a un núcleo urbano municipalse consideran sociedades tradicionales, con una unidad política cuya estructura organizativa tiene como base el régimen de Villa y Tierra. Sus integrantes son capaces de establecer vínculos comunitarios y relaciones de paz. Los vínculos son estrechos por cuestiones de índole económica y agraria, fundamentales en comunidades de tipo rural, pues la unidad se fomenta al compartir un espacio y tener la responsabilidad de cuidarlo, para el buen aprovechamiento de los pastos que alimentan el ganado, principal fuente de riqueza de esos pueblos. Además los une la defensa de todos contra el poder señorial. Sin embargo, la oligarquía de los nobles e hidalgos desangra, más que atender, a los campesinos, pequeños artesanos, etc. Por ello también encontramos pugnas entre las distintas clases sociales. En Castilla hay profundas diferencias entre los grupos existentes, lo que genera la división. En realidad no todos son prójimos porque les falta la proximidad espiritual, sólo tienen - y de manera relativa- la espacial, que no siempre los sensibiliza de los problemas y necesidades del otro.

Tal vez la mayor dificultad para este tipo de comunidades es abrirse a experiencias de mundos distintos del propio... Por eso, los castellanos pueden aceptar un rey que viene de lejos, siempre y cuando tenga vínculos de sangre con los anteriores monarcas. Lo que les resulta absolutamente inadmisible es ser gobernados por extranjeros, y que este rey sea emperador de extensos territorios, lo que obviamente, quita importancia a Castilla. Siempre será fuente de conflictos el que una potencia extranjera pretenda imponer la unidad política en contra de la diversidad de culturas, ignoradas arbitrariamente y del sentir comunitario.

De por sí en las comunidades castellanas hay un excesivo despegue cultural en el centro gravitatorio de la meseta que bloquea - por su deslumbramiento - el acompasado desarrollo plurinacional: hay cultura, pero no siempre se adopta en todos los niveles sociales, lo cual, poco a poco va provocando la desunión. Esto que es grave, se exacerba cuando Carlos V deja en los más importantes y lucrativos cargos civiles y eclesiásticos ${ }^{10}$ a ciudadanos borgoñeses, totalmente ajenos a la idiosincrasia castellana.

Los rebeldes fortalecen su espíritu comunitario y se rebelan contra los asesores o modelos extranjeros, la salida de capitales y la poca o ninguna 
presencia de la autoridad legítima. Estos rubros reflejan lo que en una comunidad con sentido de identidad y de pertenencia produce gran descontento. Su rebeldía se exacerba por la corrupción de los delegados ciudadanos frente a los sobornos del nuevo rey, porque se pierde la confianza en los que supuestamente han de velar por los intereses de la comunidad. Por tal razón se sustituye el poder de los regidores y se nombra la Junta Santa, lo cual probablemente es legítimo cuando la autoridad deja de cumplir su vocación de servicio. Pero las divisiones internas entre los grupos de poder de las comunidades quitan efectividad al movimiento.

Los castellanos quieren que se respete la fisonomía tradicional de sus reinos. Castilla encabeza la rebelión por su capacidad de liderazgo y sentido de identidad. Las comunidades responden, y aparentemente, contra las arbitrariedades del nuevo monarca, se da un sólido sentimiento de comunidad, una fuerte cohesión pues la sangre, las tradiciones y costumbres unen, pero después empieza la guerra fratricida.

El sentir de un pueblo, ya sea con base en elementos objetivos o supuestos, altruistas o mezquinos, justos o injustos, unifica a todos los que lo constituyen, crea demandas y genera una fuerza. En la medida en que tal sentimiento sea más asumido -inconsciente o conscientemente-, irá adquiriendo un vigor que dará éxito al movimiento. Por eso es tan importante - sin dejar de lado la racionalidad- mover fibras sensibles. De lo contrario el líder se quedará solo, pues vendrán otros que arrastren a las multitudes por la vía de la afectividad.

En el caso de las Comunidades castellanas llega un momento en que Padilla, como líder, destaca y el pueblo le sigue, confía en él porque encuentra respuestas a sus demandas, pero después surgen las divisiones, Padilla es sustituido por el noble Girón. Cuando el líder recupera el poder no recupera la donación primera de sus seguidores. Además, se dice que el mismo Padilla tuvo serias dudas sobre la conveniencia de seguir adelante en la lucha, por eso no logra la unidad política requerida para alcanzar el triunfo. El sentimiento de comunidad se resquebraja, los dirigentes están confundidos y divididos, y el movimiento comunero no consigue la victoria.

\section{Lo que la historia nos enseña}

Hay temas que en cada época se consideran tabúes. Con el paso del tiempo se pueden analizar, pero tal vez sea más difícil interpretarlos por falta de datos; aunque, si se logra cierta perspectiva, su estudio es aleccionador. Concretamente, el tema que nos ocupa no es de fácil comprensión, por su complejidad. 


\section{Luz María Cruz de Galindo}

Es evidente el predominio de factores políticos en las Comunidades castellanas, aunque haya discrepancias en cuanto a su sentido. A la represión siguió un silencio embarazoso de tres siglos; los historiadores locales pasaban como sobre ascuas al relatar unos hechos que para la mentalidad de la época resultaban inexplicables: la rebelión contra su soberano del más leal de los reinos ${ }^{11}$.

Algunos piensan que fue un enfrentamiento estrictamente medieval; los liberales del siglo XIX ${ }^{12}$ ven en los ideales comuneros a sus predecesores en la lucha contra la tiranía. En el siglo XX, Gregorio Marañón dice que los dirigentes -en gran parte nobles y clérigos - sólo pretendían defender sus privilegios contra un rey reformador e igualitario. José Antonio Maravall y Joseph Pérez se inclinan por dar una interpretación $m o-$ derna y democrática del movimiento. Nosotros pensamos que si efectivamente esta rebelión expresa el instinto natural del hombre por participar en las decisiones de su comunidad, si es un presagio de democracia, tal vez su fracaso se debe, en parte, al hecho de adelantarse a su época; el ambiente no lo estaba demandando, y lo lógico, lo que dictaba la inercia, era la autoridad de un rey.

En la rebelión confluyen descontentos de todo género: alborotos intrascendentes y personalistas; conversos judíos que se unen al movimiento con la esperanza - muy poco fundada - de que limitaría la autoridad de la Inquisición; una considerable agitación campesina de carácter antiseñorial; pero, sobre todo, el malestar de la clase media urbana de Castilla, por eso los grandes no se dejan arrastrar, y el ínfimo pueblo sólo actúa como comparsa. Los comuneros quieren una monarquía fuerte, nacional, que tome en cuenta a los elementos ciudadanos más responsables; una autoridad que verdaderamente dé cohesión a los reinos. El movimiento se da en la Castilla mesetaria, principal residencia de la burguesía urbana. Esta limitación geográfica quizá sea la causa primordial de su fracaso, pues no hay apoyo de otras regiones poco urbanizadas o donde predominaban los nobles.

En la rebelión los tres grandes poderes - realeza, nobleza y burguesía- pugnan por obtener un lugar preferencial para alcanzar la supremacía en la naciente España moderna. La insurrección se caldea al caer en manos de los elementos más progresistas ${ }^{13}$ del campesinado y pequeños artesanos - llenos de aspiraciones igualitarias, cuyo radicalismo asusta a la nobleza-, pero en el momento decisivo falta el apoyo popular y una actitud más protagónica de gran parte del pueblo, sobre todo del campesinado.

Conviene detenerse en estos mecanismos de conducta: aparece un motivo de inconformidad en contra de una autoridad, por parte de un de- 
terminado estrato social (burguesía). Tal actitud momentáneamente contagia a otros estratos (nobleza y plebeyos). Entonces surge el caos y la anarquía, y todos luchan contra todos, pero la clave del éxito se encuentra en:

- El apoyo popular con que se cuente.

- El apoyo de los grupos poderosos (dinero, linaje, propiedades, etc.).

- El armamento del que se dispone.

- Las estrategias (consideración de condiciones geográficas y climatológicas, etc.).

- La acción de jefes-líderes competentes que encabecen el movimiento.

- La colaboración de servidores y consejeros fieles y competentes.

- La claridad, precisión y unidad en los ideales.

- Inteligencia, maña y templanza, para actuar como más convenga.

- Un plan de acción propositivo más que reactivo.

En el manejo del conflicto comunero se pone de manifiesto la capacidad de Carlos, quien joven e inexperto, al principio no respeta la fisonomía propia de los reinos castellanos, de las que sus habitantes se sentían tradicionalmente orgullosos. Después aprende la importancia de tratar diferente a los diferentes, de conocer a sus súbditos, de ser justo y prudente con ellos y de respetar sus costumbres y tradiciones. Aprende que dirigir bien una comunidad implica el conocimiento previo y el respeto de lo que esa comunidad es. Además Carlos sabe rodearse de servidores fieles que lo mantienen siempre informado del curso de los acontecimientos, y de consejeros doctos y prudentes que le conminan a anular las disposiciones más impopulares. Así lo hace, pues un buen gobernante aunque se aferre a una idea, tarde o temprano, cuando ve la realidad, tiene que cambiar de actitud y ser justo. Esto adquiere particular relieve si su jurisdicción abarca dominios tan variados: necesita conocer y respetar las mentalidades y las culturas para poder ser aceptado por todas. Con ello su autoridad se legitima tanto de hecho como de derecho.

Por su parte los comuneros tienen serios problemas: la gran diversidad de móviles de quienes participan en la rebelión quita unidad al movimiento, faltan técnicas guerreras, mayor capacidad de movilización, y toma de decisiones en el momento oportuno. Además, la inconsistencia y radicalismo de muchos campesinos y pequeños artesanos, con sus utópicas aspiraciones igualitarias, sólo logran alejar a la nobleza de la causa comunera. Hay por tanto errores estratégicos y falta de ideales precisos. 


\section{Luz María Cruz de Galindo}

Los fines que las Comunidades se proponían alcanzar eran vagos, diversos y aun contradictorios. Había empezado por ser un movimiento municipal, pero no democrático, porque los municipios habían caído en manos de oligarquías, compuestas de caballeros, es decir, de nobles de segundo rango, cuyos intereses chocaban con los de alta nobleza y a los que poco importaba el bienestar de las clases inferiores ${ }^{14}$.

En el acontecer histórico muchas veces las causas y los efectos están separados en el tiempo, y existe el peligro, por el desconocimiento de los hechos del pasado, de ignorar o confundir las verdaderas causas y atribuirlas a otras. Pese al aparente fracaso comunero, Carlos termina por aceptar, sin ulterior discusión, la reivindicación básica de Castilla de un gobierno autóctono identificado plenamente con los castellanos. Esto es una importante enseñanza para nuestro mundo moderno. Castilla se resiste a las innovaciones que violan su autonomía, lucha en comunidad y el resultado inmediato es la pérdida de sus libertades. Pero a partir de entonces tales tierras serán gobernadas por españoles, como era su deseo. De esta manera, el inmediato fracaso se convierte en un triunfo posterior.

Ahora bien, la reiterada petición de los castellanos de «que el rey resida en estos reinos» y de que los cargos de autoridad estén en manos de españoles competentes revela la existencia de una Nación, entendida como: «Un pueblo que toma conciencia de sí mismo de acuerdo con lo realizado por la historia ${ }^{15}$. Se trata de la forma concreta de existir de una sociedad ${ }^{16}$ vinculada a al transcurso del tiempo, a la cultura, a los valores y al peculiar estilo de vida, que provocan una identidad en las personas, como fruto de una vivencia espiritual. Castilla como verdadera nación, tenía conciencia del ser propio y de su derecho a la plena existencia política, económica, social y cultural; la voluntad de ejercicio de tales derechos, por medio de la autodeterminación para configurar el propio destino y el propio futuro.

Etzioni intuyendo lo que es una colectividad organizada, hace énfasis en la importancia de que las comunidades se relacionen entre sí de una manera que resulte tan respetuosa del orden como de la autonomía. De lo contrario, sólo habrá islas comunitarias en un océano no comunitario en el que es probable que hagan su aparición la hostilidad y la lucha, e incluso que dominen el panorama. Lo importante es ser comunitarios sensibles a los derechos individuales, de tener responsabilidades sociales sin perder la propia autonomía.

El gran problema de entonces y de ahora será equilibrar el orden y la autonomía dentro de la vida comunitaria, a través de las instituciones 
sociales que alimentan los valores morales de todos. Si las tintas se cargan sobre el orden, tal vez el gobernante incurra en actitudes despóticas y prepotentes (tal como sucedió en el movimiento comunero). Si se insiste en la autonomía, es posible llegar a actitudes individualistas y poco solidarias (este era el riesgo de las Germanías). El sano equilibrio se da cuando la libertad - que no es ausencia de vínculos- se relaciona con lo óptimo; y cuando la igualdad no es igualitarismo demagógico, sino una igualdad esencial con diferencias funcionales.

Además, también se ha de encontrar y mantener un equilibrio en las relaciones entre la sociedad en general —que a finales del siglo XX todavía es una sociedad nacional-y los pequeños grupos que la integran, así como entre sociedades. Ese equilibrio, además de apuntalar la paz interior, permite que cada comunidad miembro respete sus tradiciones y su subcultura particulares y que defienda sus intereses y necesidades al mismo tiempo que colabora en el sostenimiento de un núcleo de valores compartidos. Construir y mantener una comunidad de comunidades es un reto particularmente difícil pues cuanto más fuerte es cada una, menos proclive es a considerarse y a actuar como parte de un todo más extenso. Cuanto más heterogénea es una sociedad, mayor es el desafío que afronta para conservar la autonomía intergrupal limitada en el seno de la sociedad global, como una comunidad única ${ }^{17}$. Así, en el fenómeno de la globalización, las pequeñas o medianas aldeas o ciudades no deben perder su identidad y autonomía, de lo contrario se caerá en las ya mencionadas sociedades globales artificiales que tal vez opriman, más que favorezcan, el auténtico espíritu comunitario.

\section{Decálogo del comunitario sensible}

De acuerdo con Amitai Etzioni un comunitario sensible es aquél que respeta los derechos individuales - propios y ajenos- sin dejar de cumplir sus responsabilidades dentro de la comunidad. Presentamos un decálogo que puede favorecer tanto la existencia de un orden social como la conservación de la personal autonomía. De esta manera será posible la salud social que apuesta por el individuo y al mismo tiempo estimula la diversidad expresiva; promueve el encuentro continuo con la espontaneidad, y una disposición para el enriquecimiento mutuo con lo distinto ${ }^{18}$.

El Decálogo es el siguiente:

$1^{\circ}$ Fomenta en ti mismo y en los otros una visión unitaria y global, pero que incida en lo regional.

$2^{\circ}$ Promueve un desarrollo comunitario jerárquico, al servicio de todos. 
$3^{\circ}$ Defiende y transmite los valores que sustentan la convivencia humanizada.

$4^{\circ}$ Respeta las tradiciones y la cultura universales y regionales.

$5^{\circ}$ Reconoce la identidad de cada persona y comunidad e impulsa el autodesarrollo y la participación.

$6^{\circ}$ Haz vida en ti y en los otros la experiencia de la integridad y la fidelidad.

$7^{\circ}$ Articula adecuadamente la justicia conmutativa y distributiva.

$8^{\circ}$ Genera sólo expectativas viables a corto, mediano y largo plazo.

$9^{\circ}$ Dale a la propiedad un sentido social. Evita la usura.

$10^{\circ}$ Apoya a la familia soberana.

El punto de partida para promover el comunitarismo es una actitud que parta del conocimiento de la realidad y del contexto sociohistórico y que respete las necesidades regionales, sentidas y manifiestas. De esta manera el bienestar de cada comunidad irá permeando ámbitos cada vez más amplios. Esto derivará en una promoción de desarrollo comunitario que mida las necesidades y las jerarquice, para no caer en la ampulosidad. «Pertinencia y necesidad se conforman con la demanda social a través del estudio de las funciones y disfunciones sociales que hacen referencia al momento histórico y a la situación socioeconómica concreta» ${ }^{19}$. Se trata de un servicio a próximos y lejanos. Esta idea de servicio es dispersiva y está reñida con la acumulación de poder y dinero en beneficio de unos cuantos y en detrimento de la justicia social.

En tercer lugar hablamos de una convivencia que es incluyente de la civilidad, porque humaniza el entorno social, acoge a todos y promueve el verdadero bienestar. Esto enlaza con el cuarto aspecto, pues la civilidad arropa las verdaderas tradiciones y culturas universales y regionales, cuyo requisito sine qua non es la eliminación de la desigualdad genérica ${ }^{20}$.

En quinto lugar insistimos en el respeto de la identidad individual y comunitaria. Esta identidad propiciará la raigambre y la pertenencia, el sentido comunitario, que se convertirá en la punta de lanza para el autodesarrollo y la participación Será esta una «vocación regeneradora amparada en el ansia de libertad». para ejercer el mejor servicio social posi$\mathrm{ble}^{21}$. Respecto a la experiencia de la integridad y fidelidad nos referimos a reconocer sus beneficios en la vida pasada, vivirlos en el presente y fertilizar con ellos el futuro.

Con todos estos principios se tiene preparado el campo propicio para que florezca la justicia conmutativa y distributiva que permitirá a individuos y comunidades la obtención de los satisfactores adecuados a sus distintas necesidades materiales, afectivas y espirituales. Para ello es indis- 
pensable evitar la pasividad ante las desigualdades sociales, o la actividad injusta que se adueñe de lo que es patrimonio de otros. Lo importante es lograr un sano equilibrio entre actividad y productividad equitativa. Esta justicia, unida al conocimiento de la realidad permite generar sólo expectativas viables y jamás encumbrarse con ofrecimientos demagógicos.

En cuanto al noveno punto, la propiedad con sentido social se sintetiza en dos palabras: seguridad y participación. Se trata de una mejora en la calidad de vida que incluye la promoción de propietarios, lo cual es posible si el salario es familiar, se promueve la salud y una infraestructura social acorde con las necesidades humanas. Todo ello genera seguridad en las personas y en las regiones, destierra el individualismo, gracias a una participación confiada dentro de una democracia participativa más que representativa - que canaliza y apoya propuestas e inieiativas de autogestión. Además evita la presencia de la masa que, siguiendo a Ortega y Gasset «es todo aquel que no se valora a sí mismo -en bien o en mal- por razones especiales, sino que se siente $<<$ como todo el mundo $>>y$, sin embargo, no se angusitia, se siente a sabor al sentirse idéntico a-los demás» ${ }^{22}$. El último punto del decálogo apoya a la familia sobera$n a^{23}$ y encierra una misión de excelencia porque une, integra y vincula a las personas dentro de su ámbito más noble.

Podemos preguntarnos por la pertinencia de un Decálogo del comunitario sensible en el tema de la rebelión comunera. Pensamos que este movimiento, como el de las germanías y tantos otros a lo largo de la historia, han tenido su origen en una falta de respeto a las personas y a las distintas comunidadeš, que propicia la desarticulación y el individualismo. Un comunitario sensible aprovecha los medios a su alcance, adopta actitudes y desarrolla habilidades que le permiten incidir en la vida social de manera adecuada, para lograr la excelencia social.

Recomendamos analizar a la luz de este Decálogo los distintos personajes involucrados en el movimiento comunero: Carlos V, el Cardenal Adriano de Utrech, El Cardenal Cisneros, los consejeros del Rey, los líderes del movimiento, especialmente a Juan Padilla, etc. Todos ellos paradigmas de comunitarios como mayor o menor sentido social y autonomía. ¿Por qué no también aplicar este decálogo a nuestros líderes y gobernantes contemporáneos...?

\footnotetext{
Notas

1 Cfr. PRAT DE LA RIBA. Psicología de las múltitudes. La era de las multitudes en VALleT DE GoyTisolo, Juan. Sociedad de masas y Derecho, p. 21.
} 
2 Se emplearán indistintamente los términos Comunidades, movimiento comunero y rebelión comunera.

3 Cfr. Belenguer, Ernest. El imperio hispánico, Grijalbo, Barcelona, p. 13.

4 Esto significa que las autoridades municipales toman la iniciativa. La misma palabra comunidad viene de común que quiere decir municipio.

5 Una instancia laica recibe el calificativo de santa, pues entonces como ahora, algunos aprovechan la religiosidad de los gobernados para fortalecer la autoridad civil.

6 Aguado Bleye, Pedro. Manual de historia de España. Tomo II, Espasa, Madrid, pp. $421,422$.

7 Cfr. Fernández Álvarez, Manuel. Carlos Vel rey de los encomenderos americanos, REI. México, p. 23.

8 EtzionI, A.. La nueva regla de oro, Paidos, Barcelona, p. 26.

9 Martín López, Enrique. La humanidad como ámbito máximo de convivencia. En Estudios sobre la encíclica "Solicitudo Rei Socialis", p. 402.

10 El hecho de que esos cargos fueran tan lucrativos es, de por sí, una señal de corrupción en las comunidades castellanas.

11 Domínguez Ortíz, Antonio. El antiguo Régimen: los Reyes Católicos y los Austrias, Alianza, Madrid, p. 245.

12 Cfr. Ídem, pp. 246, 247.

13 Los más pobres, ignorantes, los que tienen menos, son los que pierden poco o nada en los movimientos revolucionarios, proponen un igualitarismo absurdo, populista que finalmente desemboca en la demagogia y el poder de unos cuantos, quienes se convierten en líderes del movimiento.

14 Aguado Bleye, Pedro. Op. cit., p. 423.

15 Delos, J.T. La Nación, Tomo I, p. 74, citado por Guzmán VAldivia, Isaac. México y los caminos de la libertad, Promesa, México, p. 76.

16 GuZMÁn VAldivia, Isaac, Op. cit. p. 76.

17 Cfr. EtZioni, Amitai. Op. cit, pp. 225 a 229.

18 Cfr. PÉREZ AdÁN, José. La comunidad educativa, disertación en prensa, Pamplona, 26 de noviembre de 1999.

19 Cfr. Ídem.

20 El género es el espacio en el que en la interacción hombre-mujer se sitúan las relaciones de dominio y subordinación, las luchas por la hegemonía y las pautas de resistencia. (PÉrez AdÁn José, Sociología, p. 82.).

21 PÉrez AdÁn, José. La comunidad educativa, Disertación en prensa, Pamplona, 26 de noviembre de 1999.

22 La rebelión de las masas, Planeta, Barcelona, p. 77.

23 Cfr. PÉrez AdÁn, José. Sociología, Eunsa, Pamplona, p. 94.

\section{Bibliografía}

A.A.V.V. El municipio y la organización de la sociedad, Speiro, Madrid, 1971.

Aguado B. P. Manual de historia de España. Tomo II, $8^{a}$ edición refrendada, Editorial Espasa Calpe, S.A., Madrid, 1959.

ANDER-EGG E. Metodología y práctica de la animación sociocultural, Hvmanitas, Buenos Aires, 1986. Metodología y práctica del desarrollo de la comunidad, El Ateneo, México, 1982 . 


\section{Los comuneros: un apunte histórico}

AREndt H.. De la historia a la acción, Ediciones Paidós, España 1998. ¿Qué es la politica? Ediciones Paidós, España, 1997

BELENGUer E. El Imperio hispánico, Editorial Grijalbo Mondadori, Barcelona, 1995.

BELl D. Las contradicciones culturales del capitalismo, Editorial Patria, S.A. de C.V., México, 1977.

Bleiberg G. (Director). Diccionario de Historia de España. Tomo I, Editorial Revista de Occidente, Madrid, 1993.

DiaZ Plaja F. La historia de España en sus documentos, el siglo XVI, Instituto de Estudios Políticos, Madrid, 1958.

Domínguez Ortíz A. El antiguo Régimen: los Reyes Católicos y los Austrias, Alianza Editorial, Madrid, 1977.

Dworkin G. The Theory and Practice of Autonomy, Cambridge University Press, Nueva York, 1988.

Etzioni A. La nueva regla de oro, Ediciones Paidós Ibérica S.A. España, 1999.

FERnÁndez Álvarez M. Carlos V, el rey de los encomenderos americanos, Editorial REI México, Biblioteca Iberoamericana, $1^{a}$ edición, México, 1990.

FERNÁNDEZ F. (Coordinador). Estudios sobre la encíclica "Solicitudo Rei Socialis», AEDOS, Unión Editorial, Madrid 1990.

García DE CORTAZAR y GonZÁlez VeGa. Breve historia de España, Alianza Editorial, Madrid, 1994

GonzÁlez Uribe H. Teoría Política, Editorial Porrúa S.A. México, 1987.

Gracían Baltazar. El discreto, Editorial Porrúa S.A. México, 1986.

GUTIÉRREZ Nieto J. I. Las comunidades como movimiento antiseñorial, Barcelona, 1973. GuZMÁn VAldivia I. México y los caminos de la libertad, Editorial Promesa, México, 1986.

JOVER J. M. ${ }^{\text {. }}$ Carlos $V$ y los españoles, Biblioteca del pensamiento actual, Ediciones Rialp, Madrid, 1963.

Kisnerman N. Comunidad, Hvmanitas, Buenos Aires, 1984.

MARAVAll J. A. La revolución de las comunidades de Castilla, Madrid, 1977.

ORTEGa y GASSET J. La rebelión de las masas, Planeta D'Agostini, Barcelona, 1995.

PÉRez AdÁn J. Sociología. Conceptos y usos, EUNSA, Pamplona, 1997. La Comunidad Educativa. Disertación en prensa. Pamplona, 26 de Noviembre de 1999.

SARTORI G. ¿Qué es la democracia?, Editorial Patria S.A. de C.V., México, 1997.

VAllet DE GoYTisolo J. Sociedad de masas y Derecho, Taurus Ediciones S.A., España, 1969.

VAZQUeZ DE PRADA V. Renacimiento, Reforma, Expansión Europea. EUNSA Historia Universal, Tomo VII, Ediciones Universidad de Navarra, Pamplona, 1981. 